\title{
Modern Forms of Bank Service in Albania
}

\author{
Jehona Gjermizi, Phd Cand. \\ jehonagermizi@yahoo.com \\ Dr. Blerim Kola \\ blekola@yahoo.com
}

\begin{abstract}
Albanian banks are currently implementing e-banking. Banks that offer service via this channel claim that it reduces costs and makes them more competitive. However, many corporate consumers are not highly enthusiastic about Internet banking. An understanding of why corporate customers do not accept Internet banking can assist banks to implement this self-service technology more efficiently. In-depth qualitative interviews with Albanian firms suggest that security of the internet is a major factor inhibiting wider adoption. Those already using Internet banking seem to have more confidence that the system is reliable,whereas non-users are much more service conscious, and do not trust financial transactions made via Internet channels. Non-internet banking users tend to have more negative management attitudes toward adoption and are more likely to claim lack of resources. Legal support is also a major barrier to Internet banking adoption for corporate customers.
\end{abstract}

Keywords: Bank, Albania, Modern, Service

\section{Introduction}

In recent years, the banking sector has been an interesting case for service innovation as it moves toward using the Web for commercial purposes through Internet banking. Internet banking allows customers to have direct access to their financial information and to undertake financial transactions with no need to go to the bank. From the banks' viewpoint, use of Internet banking is expected to lead to cost reductions and improved competitiveness. This service delivery channel is seen as powerful because it can retain current Web-based customers who continue using banking services from any location. Moreover, Internet banking provides opportunities for the bank to develop its market by attracting a new customer base from existing Internet users. Things have not moved as quickly as some anticipated in turning this into reality in the banking sector. Some research shows that most consumer banking customers rank Internet banking as less important than other technology-based delivery channels, such as ATMs and telebanking. Among corporate customers, the situation seems to be similar, though somewhat less researched. Corporate customer interactions are considered to have become more intensive and complex because they involve relationships between firms and banks. These important big volume customers have not adopted Internet banking to any great extent. The potential value to be gained by customer adoption of Web-based service delivery seems to depend on overcoming some important barriers to usage.

Relatively little research has addressed the issue of barriers to Internet banking adoption. Prior studies frequently focus on positive aspects of Internet banking. In addition, Internet banking research has tended to focus on the perspective of personal account customers. There is little published work on perceptions of corporate customers about barriers to Internet banking, particularly in the context of developing countries. This research, therefore, aims to identify how corporate customers perceive barriers to usage of the Internet banking provided by Albanian banks.

\section{Internet banking and cultural context in Albania}

Albania had 3 local and 14 foreign banks offering commercial banking services at the time of this study, although exact categorization is somewhat obscured because some local banks have foreign equity and management participation. The sector is still not completely deregulated, and foreign banks are not yet allowed to open too many branches. Attempting to 
become more efficient and competitive, especially after the economic crisis, most Albanian banks have invested heavily in information technology to provide better services to their customers. They hope to reduce operating costs and generate higher long-term profits, similar to expectations by banks in many other countries. Currently, five local banks are the leaders in providing Internet banking. These banks provide fairly similar, standard services via the Internet, such as checking account balances, requesting bank statements and reports, money transfers, loan and bill payments, currency exchange, and opening letters of credit. According to bank managers interviewed in preparation for this research, banks believe this system offers improvement over traditional bill processing, helping customers cut costs and improve payment efficiency.

\section{Literature review}

The frequently cited benefits from Internet banking do not seem to materialize in every case, as the value of Web technology cannot be realized if barriers are too high. Barriers to electronic commerce in general have been classified various ways. Many elements in these discussions are related to the organization's ability to use Internet technology fully, which is one issue we examine here. A second issue is about trust in the Internet banking system and the banks that implement it. The few studies of Internet banking that examine barriers mention drawbacks such as security, privacy, and trust of Web system.

A third factor is that legal support cannot be implemented efficiently to assist customer trust in Internet banking

\section{Organizational barriers}

Organizational ability to utilize Web technology capabilities is one barrier to electronic commerce and may include management attitudes, resource constraints, and knowledge issues. A few studies have cited negative attitudes among some managers as a major hindrance. Negative attitudes cause resistance to change and lack of management commitment, reducing the company's resource allocation and motivation to use the technology . Implementing Web technology as a business channel requires some additional investment and resources, such as hardware and software.

\section{Trust of the system}

Opportunities from implementing Web technology could be restricted if there is a lack of customer trust in the Web system. Trust has been defined as:

... a willingness to rely on an exchange partner in whom one has confidence...

They viewed trust as an expectation of ability to perform, reliability, and intentionality of a partner, and proposed that trust has to be viewed as a behavioral intention or behavior that reflects dependence on the other partner .In addition, Morgan and Hunt (1994, p. 23) defined trust as:

... the perception of confidence in the exchange partner's reliability and integrity.

Both definitions underline the importance of confidence and reliability in the conception of trust. Customers frequently do not trust Internet technology for three reasons: security of the system, distrust of service providers, and worries about the reliability of Internet services. Strong concern about security is one common factor related to unwillingness to use Internet channels for commerce. Most customers are not satisfied with the infrastructure of Web security systems. In Internet banking, security is one of the most important future challenges, because customers fear higher risk in using the Web for financial transactions .Reputation is important, as distrust of the service provider is a related factor. Reputation can be defined as the extent to which customers believe a supplier or service provider is honest and concerned about its customers. Companies must have experience in business functions, policy, and support personnel to build reputations as competent technology-based service providers to their customers. For banks, reputation is one of the major factors that affect customer adoption of new technology-based service delivery. Reputation depends on policy promises to customers, including privacy policy, as most customers do not like their personal information revealed in an inappropriate manner or misused by others over the Internet . Customers who adopt electronic financial services are more likely to perceive problems related to loss of privacy, as the Internet seemingly allows other people to access their information easily . Customers do not always believe privacy policies will keep customer information confident .

Perceived risk can also cause customers to reject new technology-based service delivery. Perceived risk is related to reliability and system failure. Customers are also worried that technology-based service delivery systems will not work as 
expected, and lack confidence that problems can be solved quickly. Frequently, slow response time after the Internet interaction leads to a delay of service delivery and causes customers to be unsure that the transaction was completed .

\section{Research methodology}

Although research on barriers to electronic commerce adoption is not very extensive compared to discussion of the benefits, most of the concepts in this study have been occasionally examined before, but mostly in Western context. Using a qualitative approach provides richer detail for exploring viewpoints in early stages of research, allowing the researcher to gain a better initial understanding of the problem and to identify phenomena, attitudes and influences .

The respondents were managers in the customer firms who have responsibility for financial functions of their companies. They include financial/accounting officers and managers/directors. Two groups of respondents were targeted, the first of which consists of five corporate customers who currently operate many of their financial transactions via Internet banking. The second group consists of ten non-Internet banking customers. They were all selected by judgment sampling to cover a range of industries, e.g. finance, leasing, insurance, airline, manufacturing, and dot-com companies (Table I).

The qualitative research consisted of face-to-face in-depth interviews with corporate customers of banks that offer Internet banking. The interviews were conducted in a semi-structured format that allows respondents to express their own viewpoints .A set of interview topics guided the interviews, with a list of probing questions to draw out respondent opinions. Topics were discussed as respondents brought them up, occasionally supplemented by new issues that arose in the interviews. The interview included customer perceptions of both benefits and barriers, although this paper is only about barriers. There was no bias from forcing respondents to focus only on positive or negative issues. They could, and did, bring up both.

All in-depth interviews were conducted in Albanian language. (Quotes in the discussion were translated into English by the first author.) Extensive notes were taken during the interview. We highlighted key issues mentioned from each interview and combined the most common issues mentioned by the interviewees. To identify the major barriers to Internet banking, a qualitative content analysis is used for paraphrasing the range of significant issues. Passages and rewordings with the same or similar interpretations were summarized and categorized according to the barriers schema discussed above, although these categories were internal, not revealed to respondents. Then adopters and non- adopters were contrasted to determine possible differences.

\section{Findings: Trust is a major barrier}

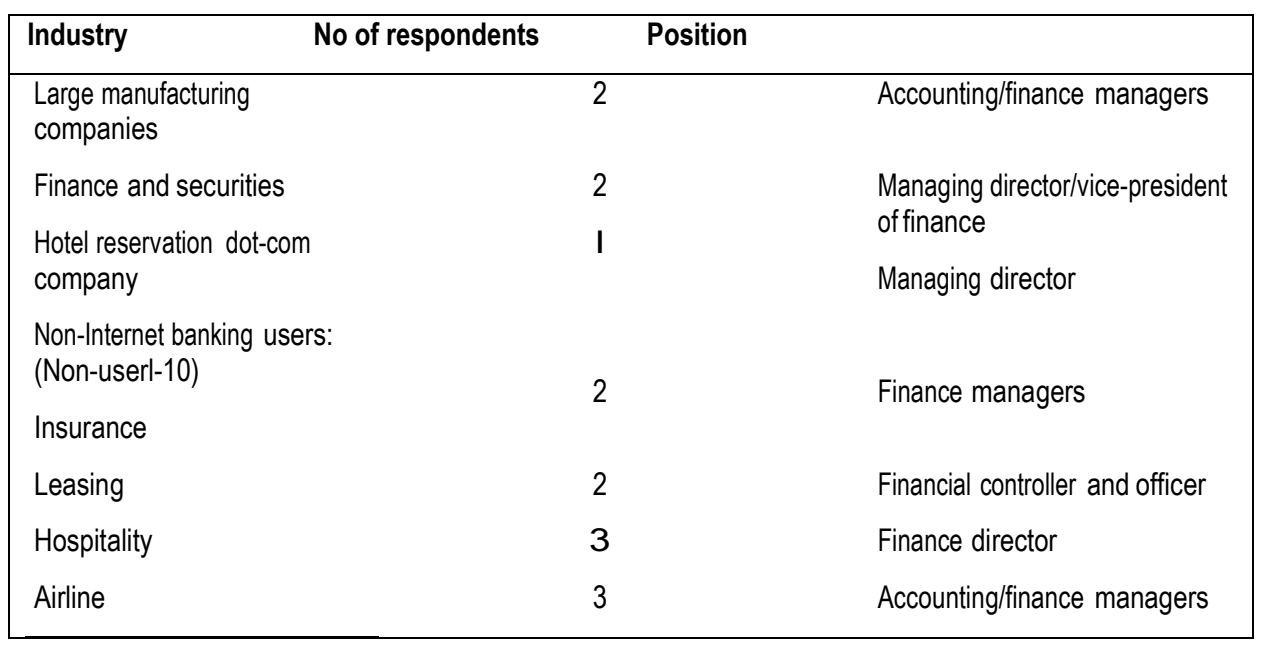

The content analysis determined nine critical barriers to Internet banking, which fall roughly into the three broad categories dis 
cussed above. Three barriers relate to trust issues: security, reliability of transactions, and trust in the service provider, including about privacy. Security is one of the major barriers. The interviews among Albanian corporate customers indicate that most Internet banking customers have adopted Internet banking as an alternative channel for their customers to make payment to them, but they do not use Internet banking for their own money transfers to other parties. This is because of concerns about security of the communication network. The following statements highlight this issue:

Although we use Internet banking, our company is concerned about security of Internet banking at some level. We believe that banks must also be concerned about security and invest intensively in security infrastructure. The reason is that most hackers normally prefer to hack directly through the bank financial systems. If any financial loss occurs to bank customers (because of this), banks have to [be] responsible for that loss (User1).

We adopt Internet banking as an additional channel for customers to make any payment to us. For internal financial transaction, such as employee salary, payment to suppliers, we use other service delivery channels, e.g. traditional money transfer or cheque payment (User3).

Non-Internet banking customers prefer to receive services directly from the banks, and have not even set up channels for their customers to use. These customers are not necessarily technology averse, e.g. some of them use non-Internet proprietary online banking software which enables banks to transfer funds or pay bills directly to bank customer accounts. However, non-Internet banking customers stay with services which are either less technologically advanced or are more closed systems, because they believe that the Internet is an open technology with easy accessibility, and thus, is not secure. Representative of these views are two quotes from respondents:

I have to remember my user name and password. I am afraid that if unauthorized personnel of my company know the password by chance or even deliberately, there will be financial risk to our company (Non-user2).

I prefer to use traditional systems, changing to Internet banking is not secure enough for financial functions that need elaborate procedures (Non-user3).

The two groups of customers also perceive reliability at different levels. Internet banking customers believe that Internet banking has some level of reliability, even though in absolute terms, it is not considered highly reliable. Non-Internet banking customers are not confident at all about doing financial transactions via the Web, and perceive Internet banking as highly untrustworthy. The following statement illustrated this point:

Business transactions normally have a great amount of money and one click may create any fraud to the firm's financial system. I don't want to absorb the financial risk and responsibility, our financial processes require originals and many copies of documents for internal control and signatures (Non-user4).

Another important issue which Internet banking users brought up is that when problems occur while making transactions via the Internet, the problem cannot be immediately resolved. Internet banking users have to go to the bank to solve such problems, which is time-consuming.

In addition, some Internet banking users are dissatisfied with the low speed of Internet banking response, which results from deficiencies in infrastructure for the Internet communication network. This causes slow feedback and slow transaction response. Their perception of convenience seems to shift once they are experienced on the Internet, and they view slow Web sites as inconvenient. Slow physical response to transactions is perceived as even more inconvenient. For example, the Managing Director of one finance company highlighted the importance of system response:

Response time is dreadful, it's very slow and keeps me waiting for ten minutes to confirm the transaction (User5).

Finally, Internet banking customers seem to choose banks which they believe have more experience in using technologybased service delivery, which is one major factor that contributes to customer trust and helps them decide whether to adopt the new service from that bank. Internet-banking customers stated that they would have less confidence using technologybased services from banks inexperienced in the technology.

Customers are also concerned about privacy in Internet banking systems, but not as much as security. Most respondents believe that they have already lost control of their personal information because Web information systems facilitate the increasingly effective dissemination of information about customers. One respondent said that he believes banks use 
customer information without customer consent whatever service delivery channel is used. It might be somewhat easier to misuse customer information if it is on the Internet, but privacy is not very safe anyway, on- or off-line. Some customers were not as cynical, but many believe that bank privacy policies are essentially the same, regardless of which servicedelivery channel is used .

\section{Barriers}

\section{Trust of the system}

Security

Reliability of transaction

Trust of the bank use internet banking provided by Albania banks

Lower level of concern

Lower level of concern

Lower level of concern, but prefer to

Do not trust the internet-based

service channels

\section{Legal support}

Fair liability

\section{Lower level of concern}

Court capability to solve online cases

efficiently

Privacy protection

Lower level of concern

Equal level of concern

\section{Organizational barriers}

Management attitude

Lack resource

Lack knowledge

Equal level of concern
Positive attitudes toward adoption

Have sufficient iT resources

Have more technical knowledge
Greater level of concern

Greater level of concern

Negative attitudes toward adoption

Lack iT resources

Have less technical knowledge

\section{Conclusions and implications}

These in-depth interviews demonstrate that there are still some serious barriers to adoption of Internet banking by Albanian corporate customers. The barriers are stronger for the non-users, but even users are not entirely comfortable with Internet banking, and have not switched most of their transactions to the Internet yet. Table II summarizes the three main types of barrier to Internet-based service delivery discussed here. Trust is one of the most critical issues, including worries about security of the system, low reliability of transactions, and distrust of the service provider. Security is a frequently cited obstacle . In our research, all customers have this concern, but non-Internet banking customers have greater levels of worry, do not have confidence to make any financial transactions via the Web, and have no intention of changing to Internet banking. 
Reliability of transactions via the Internet banking system is another major concern among all customers, but again, stronger among non-users. Users do worry about reliability of this new service, but are more confident that the bank can solve problems that arise. However, they prefer to deal with banks that have many branches, so that it is easy to go to the bank when the problems do occur. This has important implications for staff training in the branches. Even though the branches are not responsible for implementing the Internet banking, there must be someone in each branch trained to handle common Internet problems, and who knows where to go for help within the bank for more complex problems.

Finally, trust is related to experience with the bank and bank policy, which contributes to customer trust in bank business practices. The bank's overall reputation combines with reputation in technology-based service provision to make banks more or less attractive. All of these trust issues would make it difficult for new entrants, especially purely virtual banks, to make much rapid progress in developing markets among Albania corporate customers. With no prior relationships to customers, no strong reputation, and no visible prior experience with the technology, customers are unlikely to trust Internet banking services.

Albania is currently in the early stages of developing e-commerce law, and customers believe the country still lacks ability to protect bank customers sufficiently in cases of financial loss via Internet banking, and to trace online evidence and to resolve cases fairly. Further, customers are not happy with the legal support for privacy protection in Internet banking. They do not worry about this issue as much because they generally do not believe that Albania has very strong privacy protection in any service delivery channel. Banks do not have to wait for Albania law to catch up here, they can take the lead in devising policies and enforceable Internet banking contracts, which customers think are more fair than much of current practice.

Some of the trust and legal issues are partly perceptual, thus managerial attitudes are one key organizational barrier. Support or lack of desire from top management for beginning to use Internet banking seems to be critical in adoption. Nonusers have quite negative attitudes toward adopting Internet banking to replace traditional financial procedures. In addition, non-Internet banking customers do not want to invest much in information technology or training to support Internet banking adoption. Internet banking customers are not really concerned about this problem much because they already have more capability. However, even Internet banking customers do not use this channel very extensively yet. Albanian corporate customers still prefer face-to-face interaction with the banks. With trust such a strong issue, it is unlikely that this desire for close relationships will disappear. This suggests that banks will mainly develop their Internet banking from their current customer base. It seems unlikely to be an effective way to attract many new customers in the early stages of development.

To begin overcoming customer distrust of the system, banks need to visibly demonstrate concern for security, reliability, and liability with concrete solutions to reduce or eliminate costs to customers in case transactions fail or are processed inaccurately. Often, these are not purely technical issues, but rather, are related to process design, or, sometimes, partly to customer psychology and beliefs, which may or may not be consistent with the actual technology and system. All customers, even users, believe that problems will occur, so it is about what customers believe the bank will do when the problems do arise. The Internet channel must be well integrated into other channels so that customers can easily interact with people who are trained to handle problems efficiently, and banks must adopt strong customer orientations. Aside from the usage barriers, our research indicates that current users feel Internet banking is the good channel for some interactions with the bank. If it is well integrated into the overall business, the Internet can enable banks to provide more customized service, and stronger personalized relationships. Thus, customers do not seem to see the Internet as a channel to replace traditional relationships, but rather as a way to supplement and enhance the relationships. This is consistent with the cultural environment.

Banks frequently view Internet banking as essentially a cost reduction mechanism, both for themselves and for customers, but customers see quite a lot of potential new costs, partly because the new channel is perceived as much more risky. Relationships are a mechanism for reducing risk in more traditional business, and probably must also be part of the Internet banking system if it is to be widely accepted in Albania. Customers clearly say that the Internet service channel offers potential, but even users feel that it does not deliver much value yet compared to the problems of operating on the Internet. Thus, improving patronage at this stage of development seems to be mainly a matter of lowering barriers not improving benefits, and much of the work on lowering barriers seems to be about learning how to integrate the Internet into interpersonal relationships with customers. 


\section{References}

ACNielsen (2002), ACNielsen Consult Online Banking Research, available at: www.consult.com.au/

Aladwani, A. (2001), @@Online banking: a field study of drivers, development challenges and expectations", International Journal of Information Management, Vol. 21 No. 3, pp. 213-25.

Athanassopoulos, A.D. and Labroukos, N.S. (1999), @@Corporate customer behaviour

Tyler, K. and Stanley, E. (1999), @@UK bank-corporate relationships: large corporations' expectations of service", International Journal of Bank Marketing, Vol. 17 No. 4, pp. 158-70.

Walker, R.H., Craig-Lees, M., Hecker, R. and Francis, H. (2002), @@Technology-enabled service delivery: an investigation of reasons affecting customer adoption and rejection", International Journal of Service Industry Management, Vol. 13 No. 1, pp. 91-106.

Thatcher, B. (2001), @@Issues of validity in intercultural professional communication research", Journal of Business and Technical Communication, Vol. 15 No. 4, pp. 458-89.

Srijumpa, R., Speece, M. and Paul, H. (2002), @@Satisfaction drivers for Internet service technology among stock brokerage customers ", Journal of Financial Services Marketing, Vol. 6 No. 3, pp. 240-53

Gerrard, P. and Cunningham, J.B. (2003), @@The diffusion of Internet banking among consumers", International Journal of Bank Marketing, Vol. 21 No. 1, pp. 16-28.

\section{Internet References}

www.bankofalbania/org

www.bkt.com.al

http://www.raiffeisen.al/

http://www.venetobanka.al/Default.aspx

http://www.tiranabank.al/

http://www.nbg.gr/

http://www.alphabank-albania.al/

http://www.intesasanpaolobank.al/

http://www.procreditbank.com.al/

http://www.bankofalbania.org/goto.php?url_link=http://www.emporiki.com.al/\&url=http://www.emporiki.com.al\&uniqueid=2 01301251512581206\&thisMode=\&ses_userid=2

http://www.bankacredins.com/

http://societegenerale.al/

http://www.fibank.al/ 